\title{
SPAWNING OF BLACK GHOST KNIFEFISH, Apteronotus albifrons WITH DIFFERENT SEX RATIOS
}

\author{
Fajar Maulana\#, Dinar Tri Soelistyowati, and Muhammad Fadlan Furqo \\ Department of Aquaculture, Faculty of Fisheries and Marine Sciences, IPB University \\ Jl. Agatis IPB Dramaga Campus, Bogor, 16680, West Java, Indonesia
}

(Received: October 26, 2020; Final revised: March 8, 2021; Accepted: March 8, 2021)

\begin{abstract}
Black ghost knifefish, Apteronotus albifrons, is a South America-introduced ornamental fish species that has been widely cultivated in Indonesia. Some farmers breed this fish with different sex ratios, but the optimum sex ratio remains unclear. This study aimed to evaluate the spawning behavior and reproductive performance of black ghost knifefish with different sex ratios. The treatments in this study were arranged in a completely randomized design consisting of different sex ratios between males and females, namely: A (one male : three females), B (two males : three females), and C (three males : three females). Each treatment was done in triplicate. The broodstock were maintained in an aquarium $(80 \mathrm{~cm} \times 40 \mathrm{~cm} \times 40 \mathrm{~cm})$ and fed with bloodworm twice a day. The water was changed every day as much as $60 \%$ of the total volume. During the experiment, the parameters of spawning behavior, number of fish spawning, number of eggs, fertilization rate, hatching rate, and daily spawning frequencies were observed. The observation was done for seven days. The study results showed that black ghost knifefish spawned at night (11 pm - 2 am). The mating and spawning occurred between one male and one female. Competition between males was observed in the treatments indicated by aggressive movements of a male toward the others, such as sudden approaching, chasing, and driving away the others. Fish in treatment-B spawned consistently from day- 1 to day-5. Fish in treatment-A spawned from day-2 to day-4, while fish in treatment-C spawned only on day7. The reproductive performance parameters showed no significant difference in all treatments except the hatching rate parameter of treatment-B. The study concludes that better reproductive performance of black ghost knifefish, A. albifrons can be achieved with a spawning ratio of two males and three females. Further research on individual and mass spawning methods with the best spawning ratio of the fish is required.
\end{abstract}

\section{KEYWORDS: black ghost knifefish; sex ratio; spawning behavior; mating system}

\section{INTRODUCTION}

Black ghost knifefish is a fish from Gymnotiformes order, Apteronotidae family with species name Apteronotus albifrons. This fish is a unique flat shape ornamental fish with ventral and anal fish fused at the base of the tail. The color of this fish is dominated by black with a white stripe on the back and tail (Rozi et al., 2017). The fish is naturally found in South American freshwater systems such as fast-flowing rivers. This fish is a benthopelagic fish that live in the column and bottom of the water and consumes insect larvae as its main feed (U.S Fish and Wildlife Service, 2018).

\footnotetext{
\# Correspondence: Department of Aquaculture, Faculty of Fisheries and Marine Sciences, IPB University Jl. Agatis IPB Dramaga Campus, Bogor, 16680, West Java, Indonesia, Indonesia

E-mail: fajarmaulana@ apps.ipb.ac.id
}

Black ghost knifefish was introduced in Indonesia as an ornamental fish and has been cultivated ever since. Most of the fish farms rearing the fish in Indonesia are concentrated in Bogor (West Java). In fact, black ghost knifefish is one of ten popular ornamental fish in the area (Disnakan, 2017). Despite the popularity, the fish production is not yet stable (DJPB, 2019) due to the lack of standard hatching techniques that may help the fish hatcheries reaching their full production potential.

Basic reproductive information of black ghost knifefish such as spawning behavior, spawning time, and spawning substrate preference can help determine the ideal spawning condition for the fish (Rahardjo et al., 2011). This information can be used to decide the optimal sex ratio for spawning. The use of the correct sex ratio can produce the maximum number of fry. For example, rainbow fish, 
Iriatherina werneri, produces a higher quantity of eggs at one male and three females ratio (Herjayanto et al., 2016). In contrast, another rainbowfish species, Pseudomugil paskai, produce more eggs at one male and two females ratio (Wijaya, 2018). Based on these examples, the information on spawning behavior and the correct sex ratio are expected to help the black ghost knifefish cultivation. Therefore, this study aimed to evaluate the spawning behavior and reproductive performance of black ghost knifefish $A$. albifrons with different sex ratios.

\section{MATERIALS AND METHODS}

\section{Experimental Design}

This study was done in the Teaching Laboratory, Department of Aquaculture, Faculty of Fisheries and Marine Science, IPB University from August to September 2019. The treatments were arranged in a completely randomized design consisting of different sex ratios between males and females, namely: $A$ (one male : three females), B (two males : three females), and $C$ (three males : three females). Each treatment was done in triplicate. During the experiment, the parameters observed in each treatment were spawning behavior, number of fish spawning, number of eggs, fertilization rate, hatching rate, and daily spawning frequencies.

\section{Broodstock Culture}

The black ghost knifefish broodstock used in the experiment were obtained from a farmer in the Dramaga Region, Bogor, West-Java, Indonesia. The broodstocks used in the experiment were all more than one year old with the average male and female length of $23.9 \pm 2.21 \mathrm{~cm}$ and $23.4 \pm 2.56 \mathrm{~cm}$, respectively. The broodstock were initially maintained for 14 days in an aquarium of $80 \mathrm{~cm} 40 \mathrm{~cm} \times 40 \mathrm{~cm}$ in size equipped with a filter and aeration system. During the maintenance, the fish were fed twice daily with bloodworm, at $08.00 \mathrm{am}$ and $07.00 \mathrm{pm}$. The broodstocks were then stocked based on the treatment of ratio arrangement as follows: one male: three females (A), two males: three females (B), and three males: three females $(C)$.

\section{Spawning and Eggs Hatching}

Spawning observation was carried out for seven days. The spawning was done naturally where three fern roots tied to two pieces of glass were used as the substrate. The substrate was placed in the spawning aquarium at night after feeding. The fish in the aquarium was observed every one hour at night. The eggs produced by the broodstock were counted first while on the substrate. Afterward, the eggs moved into the incubation aquarium of $50 \mathrm{~cm} \times 25 \mathrm{~cm} \times 30$ $\mathrm{cm}$ in size in the morning. Water in the incubation aquarium was previously mixed with methylene blue with a dose of $5 \mathrm{mg} \mathrm{L}^{-1}$ to prevent eggs from fungal infection. The incubation was done for three days until the eggs hatched.

\section{Water Quality Management}

Water quality management was done every morning by changing the water as much as $60 \%$ of the total volume. The water changing was done after the eggs were harvested and before feeding. The measured water quality parameters consisted of temperature (Lutron D0-5510), dissolved oxygen (DO; Lutron DO5510), and pH (Lutron PH-222). The measurement was done in the morning, afternoon and night at the beginning and end of the spawning and hatching period.

\section{Statistical Analysis}

The collected data on the number of spawning, the number of eggs, fertilization rate, and hatching rate were analyzed using a non-parametric analysis of Kruskal Wallis with $95 \%$ confidence interval. The data on spawning behavior and water quality were analyzed descriptively. The data were processed using Microsoft Excel 2013 and SPSS ver. 25.

\section{RESULTS AND DISCUSSION}

Based on the observation, black ghost knifefish spawned at night to early morning between 11.00 pm - $02.00 \mathrm{am}$. As a nocturnal fish, black ghost knifefish does most of its activity at night, such as searching for prey (Nelson \& Maciver, 1999). The same behavior was observed on a fish of the same genus named brown ghost, A. leptorynchus. A. leptorynchus is more active at night than daylight (Raab et al., 2019). Henninger et al. (2018) reported that A. leptorynchus laid off eggs after intense activity at night.

There was a slight difference between the spawning behavior of fish in treatment-A and the other treatments. The female fish in treatment-A started to spawn by approaching the substrate. At the same time, all the other females stayed away from the substrate. This behavior implies that black ghost knifefish only spawn in a pair between one male and one female at any given time. The male attracted by the female started to approach the female and begin courtship around the substrate. When they were ready to spawn, the female approached the substrate with a stomach position on the substrate to lay the eggs. The male then approached the female with the stomach position led to the female stomach to fertilize the eggs (Figure 1). The fertilization was done exter- 
nally outside the body of the fish. The eggs were stuck to a gap in the substrate. After the spawning, the female stomach will be smaller than before, indicating a successful spawning.

There is a slight difference in spawning behavior between treatment-A with treatment- $B$ and $C$. There was a competition between males to mate and spawn with a female. The competition was shown by aggressive movements such as approaching quickly, chasing, or driving away other males from the female. The competition happened during the spawning process. These findings reconfirm that black ghost knifefish is an aggressive fish species, particularly during the mating period. A study conducted by Serrano-Fernández (2003) reported that the aggressiveness of black ghost knifefish is characterized by several behaviors such as swimming, chasing, or dodging other males.

The reproductive performance of black ghost knifefish, such as the number of spawning, number of eggs, fertilization rate, and hatching rate, is shown in Table 1. Another parameter such as daily spawning frequencies and water quality parameters is provided in Figure 2, Table 2, and Table 3. Based on the nonparametric statistical analysis using the Kruskal Wallis test, the results are not significant between the treatment on each parameter observed except the hatching rate.

The number of spawning obtained during the experiment showed no significant difference between the treatments. The result indicated that different sex ratios do not provide sufficient stimulation to the male to start the spawning process. Natural spawning stimulation observed in black ghost knifefish species is in the form of a low-frequency electric signal (chirp), produced in pairs by the interacting male and female of A. leptorhynchus (Hupe \& Lewis, 2008). The signal is received by the interacting individual fish, although in the process, there are competitions between individuals, especially males, to spawn with the female (Henninger et al., 2018).

The number of eggs produced during the experiment ranged between 88-231 eggs per spawning substrate (Table 1). However, statistical analysis showed

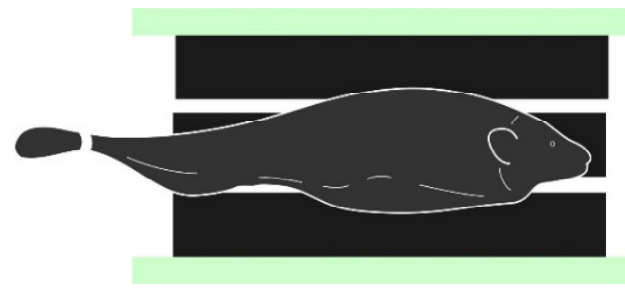

A

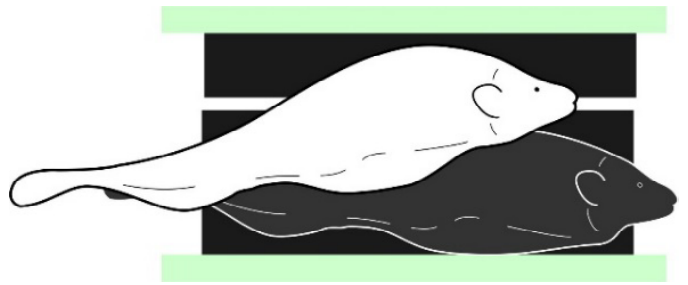

B

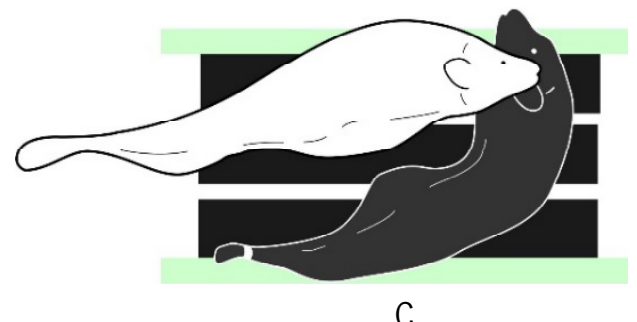

Figure 1. The illustration of observed spawning behavior between male (white) and female (black) of black ghost knifefish. The female approached the substrate (a), male approached female and started the courtship mating behavior (b), spawning between male and female (c).

Table 1. Reproductive performance of black ghost knifefish A. albifrons with different sex ratios

\begin{tabular}{lccc}
\hline \multirow{2}{*}{ Parameters } & \multicolumn{3}{c}{ Treatments } \\
\cline { 2 - 4 } & $\mathbf{A}^{*}$ & $\mathbf{B}^{*}$ & $\mathbf{C}^{*}$ \\
\hline Number of spawning (times/week) & $1 \pm 1^{\mathrm{a}}$ & $3 \pm 0.57^{\mathrm{a}}$ & $1 \pm 0.57^{\mathrm{a}}$ \\
Number of eggs (eggs/spawning substrate) & $88 \pm 50^{\mathrm{a}}$ & $231 \pm 43^{\mathrm{a}}$ & $133 \pm 108^{\mathrm{a}}$ \\
Fertilization rate $(\%)$ & $83.18 \pm 0.67^{\mathrm{a}}$ & $87.97 \pm 0.29^{\mathrm{a}}$ & $75.8 \pm 12.86^{\mathrm{a}}$ \\
Hatching rate $(\%)$ & $0^{\mathrm{a}}$ & $23.13 \pm 5.43^{\mathrm{b}}$ & $4.92 \pm 6.96^{\mathrm{a}}$ \\
\hline
\end{tabular}

Note: * one male: three females (A),two male: three females (B), three male: three females (C). Different superscript letters in the same column show significant differences $(\mathrm{P}<0.05)$ 
no significant difference in the number of eggs between the treatments. Hadinata (2013) observed the spawning black ghost knifefish population in one of the fish hatcheries in Bogor, Indonesia, and found that one black ghost fish could produce eggs approximately 200 eggs in a single spawning per spawning substrate.

The fertilization rate recorded by this study ranged from $75.03 \%$ to $88.89 \%$ (Table 1 ). This result provides important information regarding the fertilization rate of black ghost knifefish currently limited in the literature. Referring to Satyani et al. (2008), the fertilization rate can be affected by several factors such as egg quality and sperm quality. Nur \& Nurhidayat (2012) further emphasized that the fertilization rate is more affected by the quality of sperm. Based on the results of the experiment, the fertilization rate showed no significant difference between the treatments. By referring to the spawning behavior observed in this study, even in one environment consisting of more than one male and one female, the spawning still occurs but only between one male and one female.

The hatching rates found in this study showed a significant difference between treatment-B with $23.13 \%$ compared to the others treatments (Table 1 ). It is argued here the egg on the B-treatment was fertilized better than treatment- $C$ because of the competition. In contrast, in treatment-A, the fertilization was not optimal due to lack of competition (single male per treatment). However, these values are relatively low compared to the regular hatching rates of the black ghost knifefish egg at $26^{\circ} \mathrm{C}$, reaching up to $40 \%$ These low hatching rates are suspected to be caused by a possible fungal infection which was not addressed in this study. Several fungi can infect fish eggs and suppress hatching rates, such as Aspergillus sp., Penicillium sp., and Saprolegnia sp. (Kusdarwati et al., 2016).

Figure 2 shows all the spawning that happened during the seven days of observation. Spawning did not always occur together on the same day. There was a delayed period from one spawning to the next. Kirschbaum \& Schugardt (2002) mentioned that the interval spawning time on black ghost knifefish ranged between 3-17 days. However, these authors did not provide sufficient information regarding the spawning system in their experiment, especially on the ratio used. The first spawning occurred in treatment- $B$. The fish in treatment- $B$ ratio consistently spawned for the first five days and terminated on the sixth day, and continued on the seventh day. The fish in treatment-A started to spawn from the second to the fourth day and stopped on the fifth day. The fish in treatment- $C$ spawned on the seventh day and showed the lowest result compared to the other two. This is because the competition between males in treatment- $C$ is higher compared to the other treatments. In treatment-A and $B$, the competition between males was not as high as in treatment- $C$.

The water quality during the spawning period in each treatment was within the tolerable level for each parameter. Black ghost knifefish prefers temperatures between $23^{\circ} \mathrm{C}$ and $28^{\circ} \mathrm{C}$, slightly acidic water, and dissolved oxygen levels of more than $3 \mathrm{mg} \mathrm{L}^{-1}$ (Table 2 ).

The water temperature in the incubating egg aquarium ranged from $25.5^{\circ} \mathrm{C}$ to $26.3^{\circ} \mathrm{C}$. The $\mathrm{pH}$ ranged from 6.6 to 7.2 , dissolved oxygen ranged from 5.1 to $5.6 \mathrm{mg} \mathrm{L}-1$ (Table 3). All water quality parameters in both spawning and incubating aquarium were relatively within the suitable ranges.

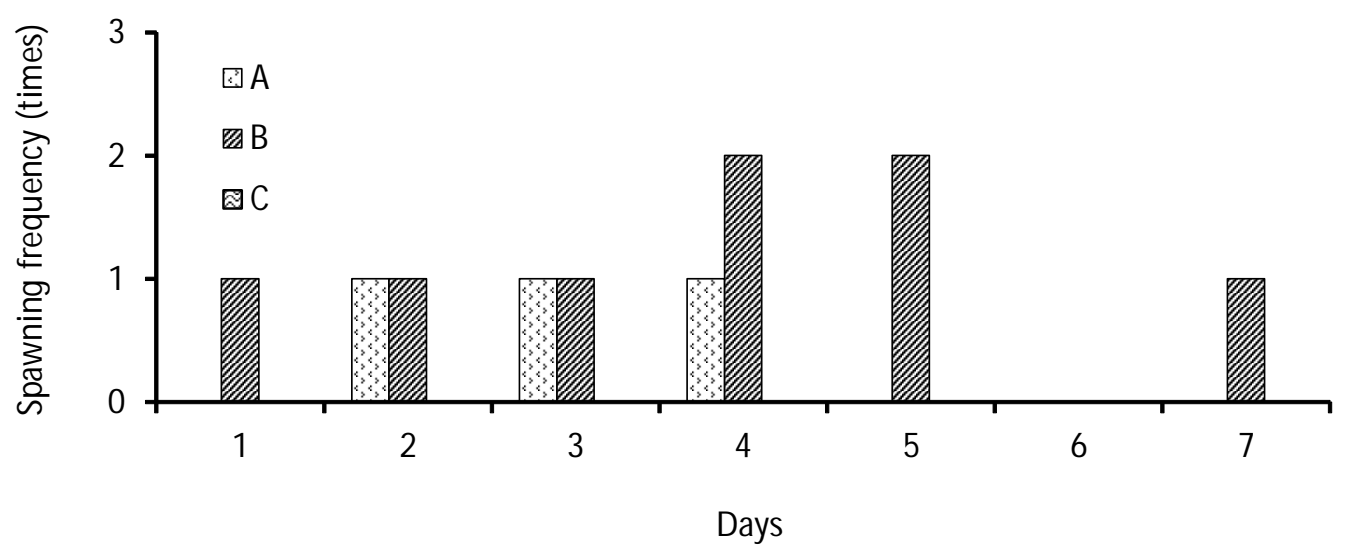

Figure 2. Daily spawning frequency of black ghost knifefish (A. albifrons) with spawning ratio of one male: three females (A), two male: three females (B), and three male: three females $(C)$. 
Table 2. Water quality on the spawning aquarium of black ghost knifefish A. albifrons spawned with different sex ratios

\begin{tabular}{lcccc}
\hline \multirow{2}{*}{ Parameters } & \multicolumn{3}{c}{ Treatments } & \multirow{2}{*}{ Reference } \\
\cline { 2 - 4 } & $\mathbf{A}^{*}$ & $\mathbf{B}^{*}$ & $\mathbf{C}^{*}$ & \\
\hline Temperature $\left({ }^{\circ} \mathrm{C}\right)$ & $23.9-25.5$ & $23.9-25.6$ & $24.0-25.6$ & $23-28^{* *}$ \\
$\mathrm{pH}$ & $6.9-7.2$ & $6.9-7.3$ & $6.9-7.2$ & $6.0-8.0^{\text {*** }}$ \\
Dissolved Oxygen/DO $(\mathrm{mg} / \mathrm{L})$ & $5.2-5.5$ & $5.2-5.6$ & $5.1-5.4$ & $>3^{* * *}$ \\
\hline
\end{tabular}

Note:

* One male : three females (A), two male : three females (B), three male : three females (C)

* U.S Fish and Wildlife Service (2018)

*** SNI $(1999 ; 2013)$

Table 3. Water quality in the incubating aquarium of eggs post-spawning of black ghost knifefish A. albifrons with different sex ratios

\begin{tabular}{lcccc}
\hline \multirow{2}{*}{ Parameters } & \multicolumn{3}{c}{ Treatments } & \multirow{2}{*}{ Reference } \\
\cline { 2 - 4 } & $\mathbf{A}^{*}$ & $\mathbf{B}^{*}$ & $\mathbf{C}^{*}$ & \\
\hline Temperature $\left({ }^{\circ} \mathrm{C}\right)$ & $25.5-26.3$ & $25.5-26.3$ & $25.6-26.3$ & $24-30^{* *}$ \\
$\mathrm{pH}$ & $6.9-7.2$ & $6.9-7.2$ & $7-7.2$ & $6.6-7.0^{* *}$ \\
Dissolved Oxygen/DO $(\mathrm{mg} / \mathrm{L})$ & $5.3-5.6$ & $5.1-5.6$ & $5.2-5.5$ & $>3^{* * *}$ \\
\hline Note: & & & \\
$* \quad$ One male : three females (A), two male : three females (B), three male : three females (C) \\
** Nugraha et al. (2012) \\
*** SNI (1999; 2013)
\end{tabular}

\section{CONCLUSION}

The black ghost knifefish spawn at night, where a female chooses a single male to spawn. There is a rivalry for spawning when more than one male was involved in the mating process. The male competitors act aggressively, approaching swiftly, pursuing, and driving away other males who try to approach the female. Except for the hatching rate in the two males and three females ratio, there is no statistically significant difference in measured reproductive performance such as spawning behavior, number of fish spawning, number of eggs, fertilization rate, and daily spawning frequency. More study is needed to determine the best spawning ratio throughout time and attain high broodstock efficiency with the optimal spawn percentage.

\section{ACKNOWLEDGMENTS}

There is no conflict of interest in this article. The authors would like to thank Alan Dwi Setiawan, S.Pi. for preparing the broodstock of black ghost knifefish and Prof. Alimuddin, Ph.D., for advice and comment for this article.

\section{REFERENCES}

Directorate General of Aquaculture [DJPB]. (2019). Performance report of the Directorate General of Aquaculture. Downloaded on December 24, 2019. Can be accessed at: https://kkp.go.id/an-component/media/upload-gambar-pendukung/DJPB/ Lkj\%20DJPB\%202018.pdf.

Bogor Regency Fisheries and Livestock Service (I.D.) [Disnakan]. (2017). Fishery data for 2017. Downloaded on July 15, 2019. Can be accessed at: https:/ /diskanak.bogorkab.go.id/data-perikanan/tahun2017/.

Henninger, J., Krahe, R., Kirschbaum, Grewe, J., \& Benda, J. (2018). Statistics on natural communication signals observed in the wild identify important yet neglected stimulus regimes in weakly electric fish. The Journal of Neuroscience, 38(24), 5456-5465.

Hadinata, P.P. (2013). Analysis of the risk of production of black ghost fish in the Arifin Fish Farm nursery unit I, Bogor City, West Java. Thesis. Bogor (ID): Institut Pertanian Bogor.

Herjayanto, M., Carman, O., \& Soelistyowati, D.T. (2016). Spawning behavior, reproductive potential of female fish, and optimization of rainbow fish spawning techniques Iriantherina werneri Meinken, 1947. Jurnal Ikthiologi Indonesia, 16(2), 171-183.

Hupé, G.J. \& Lewis, J.E. (2008). Electrocommunication signals in free swimming brown ghost knifefish, 
Apteronotus leptorhynchus. Journal of Experimental Biology, 211(10), 1657-1667.

Kirschbaum, F. \& Schugardt, C. (2002). Reproductive strategies and developmental aspects in mormyd and gymnotiform fishes. Journal of Physiology, 96, 557-677.

Kusdarwati, R., Sudarno, \& Hapsari, A. (2016). Isolation and identification of fungi in goldfish (Carrasios auratus) at the Gunung Sari Ornamental Fish Exchange, Surabaya, East Java. Jurnal IImiah Perikanan dan Kelautan, 8(1), 1-15.

Nelson, M.E. \& Maciver, M.A. (1999). Prey capture in the weakly electric fish Apteronotus albifrons: Sensory acquisition strategies and electrosensory consequences. The Journal of Experimental Biology, 202, 1195-1203.

Nugraha, D., Supardjo, M.N., \& Subiyanto. (2012). The effect of temperature differences on embryo development, hatchability of eggs and absorption rate of black ghost fish egg yolk (Apteronotus albifrons) on a laboratory scale. Journal of Management of Aquaculture Resource, 1(1), 1-6.

Nur, B. \& Nurhidayat. (2012). Optimization of the reproduction of the rainbow curumo fish, Melanotaenia parva Allen, 1990 through the ratio of the parent sex in spawning. Jurnal Iktiologi Indonesia, 12(2), 99-109.

Indonesian National Standard [SNI]. (2013). Production of black ghost ornamental fish (Apteronotus albifrons). Downloaded October 28, 2019. Can be accessed at: https://bsn.go.id/uploads/download/ buletin_SNI_Ed_3_Final_reduced_web1.pdf.

Indonesian National Standard [SNI]. (1999). Production of goldfish (Cyprinus carpio Linneaus),
Sinyonya strain of seed class. Downloaded: December 4, 2019. Can be accessed on: http:// kkp.go.id/an-component/media/upload-gambarpendukung / D I T \%2 OPERBEN I HAN / SNI\%20Perbenihan/SNI\%20Mas\%20Sinyonya/31_016137-1999.pdf.

Raab, T., Linhart, L., Wurm, A., \& Benda, J. (2019). Dominance in habitat preference and diurnal explorative behavior of the weakly electric fish Apteronotus leptorhynchus. Fronteirs in Integrative Neuroscience, 13(21), 1-9.

Rahardjo, M.F., Sjafei, D.S., Affandi, R., \& Sulistiono. (2011). Iktiologi. Bandung (ID): Lubuk Agung.

Rozi, F., Rusliadi, \& Putra, I. (2017). Provision of different natural foods for black ghost fish (Apteronotus albifront). Berkala Perikanan Terubuk, 45(2), 19-29.

Satyani, D., Subandiyah, S., \& Insan, I. (2008). The use of two types of gonadotropin hormones to stimulate spawning of balashark fish (Balanteocheilus malanopterus). Jurnal Riset Akuakultur, 3(2), 157-164.

Serrano-Fernández, P. (2003). Gradual frequency rises in interacting black ghost knife fish, Apteronotus albifrons. Journal Comp Physiol A., 189, 685-692.

U.S Fish and Wildlife Service. (2018). Black ghost knifefish (Apteronotus albifrons). Downloaded October 28, 2019. Can be accessed on: https:// www.fws.gov/fisheries/ANS/erss/uncertainrisk/ ERSS-Apteronotus-albifrons-FINAL.pdf.

Wijaya, H.K. (2018). Optimization of the spawning of rainbow fish (Pseudomugil paskai) with different sex ratios of broodstock. Thesis. Bogor (ID): Institut Pertanian Bogor. 